Published in final edited form as:

J Gastrointest Surg. 2018 April ; 22(4): 661-667. doi:10.1007/s11605-017-3650-4.

\title{
Clinical factors and postoperative impact of bile leak after liver resection
}

\author{
Allison N. Martin, MD, MPH ${ }^{\mathrm{a}}$, Sowmya Narayanan, PhDa, Florence E. Turrentine, PhD, RNa, \\ Todd W. Bauer, MDa, Reid B. Adams, MDa ${ }^{a}$ George J. Stukenborg, PhD ${ }^{\mathrm{a}}$, and Victor M. \\ Zaydfudim, MD, MPH ${ }^{a, b}$ \\ aDepartment of Surgery, University of Virginia, Charlottesville, VA, USA \\ bSurgical Outcomes Research Center, University of Virginia, Charlottesville, VA
}

\section{Abstract}

Background-Despite technical advances, bile leak remains a significant complication after hepatectomy. The current study uses a targeted multi-institutional dataset to characterize perioperative factors that are associated with bile leakage after hepatectomy and to better understand the impact of bile leak on morbidity and mortality.

Methods-Adult patients in the 2014-2015 ACS NSQIP targeted hepatectomy dataset were linked to the ACS NSQIP PUF dataset. Bivariable and multivariable regression analyses were used to assess the associations between clinical factors and post-hepatectomy bile leak.

Results-Of 6,859 patients, $530(7.7 \%)$ had a postoperative bile leak. Proportion of bile leaks was significantly higher in patients after major compared to minor hepatectomy ( $12.6 \%$ vs $5.1 \%$, $\mathrm{p}<0.001)$. The proportion of patients with bile leak was significantly higher in patients after major hepatectomy who had concomitant enterohepatic reconstruction $(31.8 \%$ vs $10.1 \%, \mathrm{p}<0.001)$. Postoperative mortality was significantly higher in patients with bile leaks $(6.0 \%$ vs $1.7 \%$, $\mathrm{p}<0.001)$. After adjusting for significant covariates, bile leak was independently associated with

Corresponding Author: Victor M. Zaydfudim, MD, MPH, Assistant Professor of Surgery, Section of Hepatobiliary and Pancreatic Surgery, Box 800709, University of Virginia, Charlottesville, VA 22908-0709, Phone: (434) 924-2839, Fax: (434) 982-4778, vz8h@virginia.edu.

Presented in part at the 2017 Annual Meeting of the Americas Hepato-Pancreato-Biliary Association, March 29-April 2, 2017, Miami, FL.

Disclosure Information: Nothing to disclose

Statement of Author Contribution

Category 1

Conception and design of study: Martin, Stukenborg, Zaydfudim

Acquisition of data: Martin, Narayanan, Turrentine

Analysis and/or interpretation of data: Martin, Narayanan, Turrentine, Bauer, Adams, Stukenborg, Zaydfudim

Category 2

Drafting the manuscript: Martin, Narayanan, Turrentine

Revising the manuscript critically for important intellectual content: Bauer, Adams, Stukenborg, Zaydfudim

Category 3

Final approval of the version of the manuscript to be published: Martin, Narayanan, Turrentine, Bauer, Adams, Zaydfudim

G. Stukenborg significantly contributed to the entire project including manuscript composition and revision prior to his sudden and untimely death at the end of Summer 2017.

Category 4

Agreement to be accountable for all aspects of the work: Martin, Narayanan, Turrentine, Bauer, Adams, Stukenborg (posthumously),

Zaydfudim 
increased risk of postoperative morbidity ( $\mathrm{OR}=4.55 ; 95 \% \mathrm{CI}: 3.72-5.56$; $\mathrm{p}<0.001$ ). After adjusting for significant effects of postoperative complications, liver failure, and reoperation; bile leak was not independently associated with increased risk of postoperative mortality ( $\mathrm{p}=0.262)$.

Conclusion-Major hepatectomy and enterohepatic biliary reconstruction are associated with significantly higher rates of bile leak after liver resection. Bile leak is independently associated with significant postoperative morbidity. Mitigation of bile leak is critical in reducing morbidity and mortality after liver resection.

\section{Introduction}

Despite significant improvements in perioperative mortality, morbidity after liver resection remains $>20 \%$ [1-4]. Among complications, bile leakage remains a technical challenge which has the potential to be improved with surgical technique. Single institution studies suggest various bile leak mitigation strategies with reported bile leak rates as low as 1\% [5]. Recent multi-institutional American College of Surgeons National Surgical Quality Improvement Program (ACS NSQIP) collaborative studies reported bile leak rates approximating 7\% [6,7]; however, factors associated with a considerably higher proportion of bile leaks are largely unexplored.

Extent of resection, operative approach, vessel sealing strategies, post-resection cholangiograms, and use of postoperative drains have all been suggested as factors associated with higher or lower risk of bile leak [8-10]. Associations between bile leak and other clinical factors such as re-operative surgery, long operating time, and bleeding requiring blood transfusion, have also been described [11-13]. While the impact of this complication at centers with very low rates of bile leak is difficult to define, bile leak remains a morbid complication across the majority of hepatobiliary centers.

ACS NSQIP has been recently expanded to include procedure-specific targeted modules for clinically relevant data collection. The current hepatectomy module includes procedurespecific definitions of complications including bile leak, use of drains, and liver failure among others. We aimed to evaluate the impact of clinically relevant factors on posthepatectomy bile leak and to estimate the associations between post-hepatectomy bile leak and morbidity and mortality.

\section{Methods}

\section{Variable selection and outcome definitions}

ACS NSQIP is a Health Insurance Portability and Accountability Act (HIPAA) compliant dataset that includes patient-level, aggregated data from participating hospitals nationwide. It is considered a public data set and has been designated exempt by the University of Virginia Institutional Review Board (UVA IRB) for Health Sciences Research (HSR). The targeted hepatectomy module became available starting in 2014. All adult patients $\geq 18$ years of age in the 2014 and 2015 ACS NSQIP hepatectomy targeted datasets were linked to the 2014 and 2015 ACS NSQIP Public Use File (PUF) datasets for this retrospective cohort study. 
Demographic and clinical variables were abstracted from the linked ACS NSQIP PUF and targeted hepatectomy datasets. Demographic variables included age, sex, race, ethnicity, body mass index (BMI), diabetes, and tobacco and/or alcohol use. Clinical variables included presence of bile leak, operative diagnosis (categorized as benign or malignant), extent of resection, operative approach (minimally invasive or open), length of stay, concomitant bile duct resection and enterohepatic reconstruction and occurrence of postoperative morbidity and mortality. Extent of resection was categorized based on procedure type according to the index operation using current procedural terminology (CPT): minor hepatectomy (47120) and major hepatectomy (47122, 47125, and 47130). Final pathology report summarized in the ACS NSQIP using the International Classification of Diseases, $9^{\text {th }}$ revision (ICD-9) codes was used to categorize each case as benign or malignant. Malignant tumors include both primary hepatobiliary cancers and secondary, or metastatic, tumors. Benign tumors include hepatic adenomas, abscesses, focal nodular hyperplasia, hemangioma, and other benign indications for liver resection. Fifty-nine patients had missing bile leak variable in the linked data set and were excluded from the study. In addition, seven patients with an unknown or missing final pathologic diagnosis and/or those with an ICD-9 code indicating "neoplasm of uncertain behavior" were also excluded from the analysis.

The primary outcome was postoperative bile leak, defined according to the International Study Group of Liver Surgery (ISGLS) definitions [14], which are used by the ACS NSQIP targeted module. In summary, bile leaks are defined clinically as drain bile levels three times the upper limit of the normal serum total bilirubin level or as persistent drainage requiring continuation of an intraoperatively placed drain after postoperative day three or placement of a new drain. Grade A leaks do not require additional intervention. Grade B leaks require therapeutic intervention such as endobiliary decompression and/or percutaneous drainage. Grade $\mathrm{C}$ leaks require management with reoperation and include life-threatening biliary peritonitis or multi-organ failure [14]. Secondary outcomes included mortality, readmission, and reoperation and were defined using standard NSQIP definitions of 30-day occurrences. Liver failure (defined using ISGLS definition), presence of preoperative biliary stent, and presence of surgical drain were included from targeted module data abstraction. Composite all-cause 30-day morbidity was defined as the occurrence of one or more of the following NSQIP-defined complications: pneumonia, reintubation, failure to wean off the ventilator, renal insufficiency, renal failure, cardiac arrest, myocardial infarction, stroke, sepsis, septic shock, fascial dehiscence, organ space infection, or venous thromboembolism (deep vein thrombosis and/or pulmonary embolism).

\section{Data analysis}

Categorical variables were compared using chi-square or Fisher's exact test, as appropriate. Continuous variables are reported as medians with interquartile range and were compared using Wilcoxon rank sum. Bivariable comparisons were performed to assess the associations between clinical factors and occurrence of post-hepatectomy bile leak in the entire cohort and among patients who had major hepatectomy. Two separate multivariable models were developed to estimate the independent effect of bile leak on morbidity and mortality after liver resection. Clinical variables included in the bivariable logistic regression for both 
morbidity and mortality model were selected a priori; variables with significant effects $(\mathrm{p}<0.10)$ were included in the multivariable analyses. The threshold for statistical significance was set at an alpha level of 0.05. Stata version 14.2 (StataCorp LP, College Station, TX) software was used for data management and statistical analysis.

\section{Results}

\section{Patient demographics}

A total of 6,859 patients, median age 60 (interquartile range [IQR] 50-68), were included in the study. More patients were female $(\mathrm{n}=3,546,51.7 \%)$, most were White $(\mathrm{n}=4,426,64.5 \%)$, and median BMI was 27.3 (IQR 23.9-31.4). The majority of patients had minor hepatectomy $(4,430,64.6 \%)$ for a malignant indication $(n=5,226,76.2 \%)$ and had an American Society of Anesthesiologists (ASA) class of $3(n=4,484,65.4 \%)$. Most patients were non-smokers $(\mathrm{n}=5,833,85.0 \%)$ and non-diabetic $(\mathrm{n}=5,743,83.7 \%)$.

\section{Postoperative bile leak}

Of 6,859 patients, 530 (7.7\%) patients had a postoperative bile leak. Demographic and clinical covariates stratified by presence of bile leak are summarized in Table 1. Grade A leaks were the most common $(n=278,52.5 \%)$, followed by grade $B(n=204,38.5 \%)$ and grade $\mathrm{C}$ leaks $(\mathrm{n}=48,9.1 \%)$. Demographic covariates did not differ between the two groups. There was no difference in rate of severe, grade $\mathrm{C}$, bile leaks between patients who had major versus minor hepatectomy (9.8\% vs $8.0 \%, \mathrm{p}=0.359)$. Major hepatectomy, malignant indication for resection, neoadjuvant therapy, longer operative time, concomitant enterohepatic reconstruction, preoperative biliary stent, and presence of surgical drain were all associated with postoperative bile leak (all $\mathrm{p} \unlhd$ (0.006). Within the entire study cohort, patients who had minimally invasive resection were less likely to have a bile leak compared to patients who had open resection ( $3.9 \%$ vs $8.9 \%, \mathrm{p}<0.001)$. All measured postoperative complications including liver failure ( $20.2 \%$ vs $4.1 \%$ ), re-operation $(12.1 \%$ vs $2.2 \%$ ), readmission ( $35.7 \%$ vs $8.5 \%$ ), sepsis or septic shock ( $28.3 \%$ vs $4.8 \%)$, and death (6.0 vs $1.7 \%$ ) were associated with postoperative bile leak (all $\mathrm{p}<0.001$, Table 1$)$.

The proportion of bile leaks was significantly higher in patients after major hepatectomy compared to minor hepatectomy ( $12.6 \%$ vs $5.1 \%$, p $<0.001)$. Factors associated with bile leaks after major hepatectomy are summarized in Table 2 . Among patients who had major hepatectomy $(n=2,429)$, malignant diagnosis, concomitant enterohepatic reconstruction, and presence of surgical drain were associated with diagnosis of bile leak (all $\mathrm{p} \unlhd$ (007). Excluding patients with Grade A leaks, presence of surgical drain was associated with both Grade B and Grade C bile leaks (both $\mathrm{p}<0.001$ ). There was no difference in Grade B or Grade $\mathrm{C}$ bile leaks in patients who had or did not have a surgical drain stratified by extent of hepatectomy (both $\mathrm{p} \searrow 0.092$ ).

Proportion of bile leak after enterohepatic reconstruction varied from $29.1 \%$ in the entire cohort to $31.8 \%$ among patients who had concomitant major hepatectomy. Proportions of bile leak in patients who had minimally invasive and open major hepatectomy were similar $(9.2 \%$ vs $12.7 \%, \mathrm{p}=0.081)$. Excluding patients who had enterohepatic reconstruction, 
proportions of bile leak after minimally invasive and open hepatectomy were also not significantly different $(6.9 \%$ vs $9.9 \%, \mathrm{p}<0.117)$. Preoperative biliary stenting was highly correlated with enterohepatic reconstruction. Among 34\% of patients who had preoperative biliary stent, but did not have enterohepatic reconstruction, presence of preoperative biliary stent was associated with postoperative bile leak ( $16.5 \%$ vs $5.9 \%, \mathrm{p}<0.001)$. Similar to the entire cohort, patients with a bile leak after major hepatectomy were significantly more likely to have other postoperative complications, including reoperation, readmission, septic shock or sepsis, and death (all $\mathrm{p}<0.001$ ).

\section{Multivariable analysis}

Two separate logistic regression models tested the effects of clinically relevant covariates on morbidity and mortality after liver resection. Bile leak, perioperative blood transfusion, longer operative time, major hepatectomy and enterohepatic reconstruction were all significantly associated with morbidity after hepatectomy (all $\mathrm{p}<0.001$ ), Table 3 . Bile leak remained a statistically significant factor $(\mathrm{OR}=4.55 ; 95 \% \mathrm{CI}: 3.72-5.56 ; \mathrm{p}<0.001)$ associated with post-hepatectomy morbidity after adjusting for covariates; model C-statistic 0.73. Bile leak, liver failure, reoperation, and composite NSQIP complications were associated with mortality after hepatectomy (all $\mathrm{p}<0.001$ ), Table 4 . After adjusting for independent effects of liver failure, reoperation, and composite NSQIP complications (all $\mathrm{p}<0.001$ ), bile leak was not an independent factor associated with post-hepatectomy mortality $(\mathrm{OR}=0.77 ; 95 \%$ CI: $0.48-1.22 ; \mathrm{p}=0.262)$; model C-statistic 0.90 .

\section{Discussion}

In this multi-institutional, independent data collection analysis of patients who had liver resection in 2014 and 2015, nearly 8\% of patients developed bile leak after hepatectomy. Proportion of bile leak after major hepatectomy is greater than $12 \%$, which is significantly higher than the proportion of bile leak after minor liver resection; the proportion of bile leaks after hepatectomy with bile duct reconstruction exceeds $29 \%$. These statistics are important. Bile leak is associated with every clinically important complication after liver resection including: sepsis, organ space infection, prolonged length of hospitalization, readmission, re-operation, liver failure, and composite NSQIP-defined complication.

Previously established clinically important factors such as concomitant bile duct reconstruction, blood transfusion, and extent of resection were associated with postoperative morbidity in the present study. Importantly, bile leak was an independent variable significantly associated with postoperative morbidity after adjusting for other covariates. However, after adjusting for clinically relevant effects of liver failure, reoperation, and composite NSQIP complications, bile leak did not have an independent association with post-hepatectomy mortality.

Higher morbidity and mortality of concomitant major hepatectomy with bile duct resection and reconstruction has been described previously. Patients resected for perihilar cholangiocarcinoma are in a particularly high-risk group with risk of perioperative mortality exceeding $8-10 \%$ at experienced centers $[15,16]$. A single-institution study evaluating effects of clinical covariates on bile leak identified both extent of liver resection and bile 
duct resection and reconstruction as independent covariates associated with bile leak after hepatectomy [11]. Additive negative effects of major hepatectomy and malignant diagnosis have also been described. A recent ACS NSQIP study using data collected prior to the targeted hepatectomy dataset demonstrated the highest morbidity and mortality among patients who had major hepatectomy for primary liver malignancy including hepatocellular carcinoma and intrahepatic cholangiocarcinoma [17].

When evaluating all patients reported in the combined targeted hepatectomy ACS NSQIP PUF dataset, the proportion of bile leaks after minimally invasive liver resection was significantly less than after open resection. However, among patients who underwent major hepatectomy, the proportion of bile leaks between operative approaches did not differ. The proportion of bile leaks after minimally invasive liver resection in this study, nearly $4 \%$ in the entire cohort and over 9\% after major hepatectomy, is significantly greater than the $1.5 \%$ bile leak occurrence reported in a review of nearly 3,000 aggregated cases from composite aggregate of the published literature [18].

The relationship between surgical drains and bile leaks is important to discuss. In this study, as in most retrospective analyses, presence of a surgical drain was associated with presence of a leak. The association between operative site drainage and bile leak was recently explored using the ACS NSQIP targeted hepatectomy dataset [6]. Using propensity-matched analysis, this study demonstrated similar proportions of major bile leaks that required intervention between patients with and without an operatively placed drain. In contrast, patients with drains had significantly higher likelihood of minor bile leaks that did not require intervention compared to patients without a drain. Despite already having a drain, patients with surgical drains underwent more postoperative interventions compared to patients without an operatively placed drain. However, cautious interpretation of these data is required. While a number of retrospective analyses suggested lack of benefit to drains after pancreaticoduodenectomy [19, 20], a recent multi-institutional randomized controlled trial was stopped prior to study completion by Data Safety Monitoring Board as a result of increase in mortality from $3 \%$ in patients with a drain to $12 \%$ in patients without operative site drainage [21]. While limited use of drains after liver resection should be considered, further prospective data might help understand and mitigate risk in patients after high risk operations (such as extended resections and enterohepatic reconstruction). Patients with bile leaks after major hepatectomy and enterohepatic reconstruction are at highest risk for postoperative complications including infections, bleeding and reoperation [22, 23].

Multiple studies have examined strategies for diagnosis and mitigation of risk of bile leak after hepatectomy [5, 10, 24-27]. Proposed options for decreasing bile leaks have included operative site drainage, nasobiliary drainage, sealants, and completion cholangiograms. Routine use of both air and contrast cholangiograms have been associated with reduced risk of postoperative bile leaks in multiple studies [5, 27, 28]. Air cholangiograms, in particular, offer an elegant and technically reproducible method for post hepatectomy bile leak detection without need for contrast injection or use of fluoroscopy [5]. Barriers to routine use of completion cholangiograms are largely unexplored, but are likely related to additional operative time and perceived inconvenience. Given a relatively high rate of bile leaks, routine cholangiography should be considered in patients after major hepatectomy. 


\section{Conclusions}

Nearly $8 \%$ of patients have bile leak after liver resection. Proportion of bile leak is especially high after major hepatectomy and/or enterohepatic reconstruction. Bile leak is independently associated with significant postoperative morbidity. Mitigation of bile leak is imperative to improve postoperative complications in patients after hepatectomy.

\section{Acknowledgments}

The American College of Surgeons National Surgical Quality Improvement Program and the hospitals participating in the ACS NSQIP are the source of the data used herein; they have not verified and are not responsible for the statistical validity of the data analysis or the conclusions derived by the authors. This study was supported in part by funding support provided by the Institutional National Research Service Award T32 CA 163177 from the National Cancer Institute to ANM and Loan Repayment Program Award 1 L30 CA220861-01 from the National Cancer Institute to VMZ.

\section{References}

1. Dimick JB, Wainess RM, Cowan JA, Upchurch GR Jr, Knol JA, Colletti LM. National trends in the use and outcomes of hepatic resection. J Am Coll Surg. 2004; 199(1):31-8. DOI: 10.1016/ j.jamcollsurg.2004.03.005 [PubMed: 15217626]

2. Foster JH, Berman MM. Solid liver tumors. Major Probl Clin Surg. 1977; 22:1-342. [PubMed: 839860]

3. Jarnagin WR, Gonen M, Fong Y, DeMatteo RP, Ben-Porat L, Little S, et al. Improvement in perioperative outcome after hepatic resection: analysis of 1,803 consecutive cases over the past decade. Ann Surg. 2002; 236(4):397-406. discussion -7. DOI: 10.1097/01.SLA. 0000029003.66466.B3 [PubMed: 12368667]

4. Yokoo H, Miyata H, Konno H, Taketomi A, Kakisaka T, Hirahara N, et al. Models predicting the risks of six life-threatening morbidities and bile leakage in 14,970 hepatectomy patients registered in the National Clinical Database of Japan. Medicine (Baltimore). 2016; 95(49):e5466.doi: 10.1097/MD.0000000000005466 [PubMed: 27930526]

5. Zimmitti G, Vauthey JN, Shindoh J, Tzeng CW, Roses RE, Ribero D, et al. Systematic use of an intraoperative air leak test at the time of major liver resection reduces the rate of postoperative biliary complications. J Am Coll Surg. 2013; 217(6):1028-37. DOI: 10.1016/j.jamcollsurg. 2013.07.392 [PubMed: 24246619]

6. Brauer DG, Nywening TM, Jaques DP, Doyle MB, Chapman WC, Fields RC, et al. Operative Site Drainage after Hepatectomy: A Propensity Score Matched Analysis Using the American College of Surgeons NSQIP Targeted Hepatectomy Database. J Am Coll Surg. 2016; 223(6):774-83e2. DOI: 10.1016/j.jamcollsurg.2016.09.004 [PubMed: 27793459]

7. Spolverato G, Ejaz A, Kim Y, Hall BL, Bilimoria K, Cohen M, et al. Patterns of care among patients undergoing hepatic resection: a query of the National Surgical Quality Improvement Programtargeted hepatectomy database. J Surg Res. 2015; 196(2):221-8. DOI: 10.1016/j.jss.2015.02.016 [PubMed: 25881789]

8. Alexiou VG, Tsitsias T, Mavros MN, Robertson GS, Pawlik TM. Technology-assisted versus clampcrush liver resection: a systematic review and meta-analysis. Surg Innov. 2013; 20(4):414-28. DOI: 10.1177/1553350612468510 [PubMed: 23242518]

9. Kaibori M, Ishizaki M, Matsui K, Kwon AH. Intraoperative indocyanine green fluorescent imaging for prevention of bile leakage after hepatic resection. Surgery. 2011; 150(1):91-8. DOI: 10.1016/ j.surg.2011.02.011 [PubMed: 21514613]

10. Lam CM, Lo CM, Liu CL, Fan ST. Biliary complications during liver resection. World J Surg. 2001; 25(10):1273-6. [PubMed: 11596889]

11. Zimmitti G, Roses RE, Andreou A, Shindoh J, Curley SA, Aloia TA, et al. Greater complexity of liver surgery is not associated with an increased incidence of liver-related complications except for 
bile leak: an experience with 2,628 consecutive resections. J Gastrointest Surg. 2013; 17(1):57-64. discussion p -5. DOI: 10.1007/s11605-012-2000-9 [PubMed: 22956403]

12. Okumura K, Sugimachi K, Kinjo N, Shoji F, Ikebe M, Makino I, et al. Risk factors of bile leakage after hepatectomy for hepatocellular carcinoma. Hepatogastroenterology. 2013; 60(127):1717-9. [PubMed: 24634941]

13. Sadamori H, Yagi T, Shinoura S, Umeda Y, Yoshida R, Satoh D, et al. Risk factors for major morbidity after liver resection for hepatocellular carcinoma. Br J Surg. 2013; 100(1):122-9. DOI: 10.1002/bjs.8957 [PubMed: 23175234]

14. Koch M, Garden OJ, Padbury R, Rahbari NN, Adam R, Capussotti L, et al. Bile leakage after hepatobiliary and pancreatic surgery: a definition and grading of severity by the International Study Group of Liver Surgery. Surgery. 2011; 149(5):680-8. DOI: 10.1016/j.surg.2010.12.002 [PubMed: 21316725]

15. Wiggers JK, Groot Koerkamp B, Cieslak KP, Doussot A, van Klaveren D, Allen PJ, et al. Postoperative Mortality after Liver Resection for Perihilar Cholangiocarcinoma: Development of a Risk Score and Importance of Biliary Drainage of the Future Liver Remnant. J Am Coll Surg. 2016; 223(2):321-31e1. DOI: 10.1016/j.jamcollsurg.2016.03.035 [PubMed: 27063572]

16. Zaydfudim VM, Rosen CB, Nagorney DM. Hilar cholangiocarcinoma. Surg Oncol Clin N Am. 2014; 23(2):247-63. DOI: 10.1016/j.soc.2013.10.005 [PubMed: 24560109]

17. Shubert CR, Habermann EB, Truty MJ, Thomsen KM, Kendrick ML, Nagorney DM. Defining perioperative risk after hepatectomy based on diagnosis and extent of resection. J Gastrointest Surg. 2014; 18(11):1917-28. DOI: 10.1007/s11605-014-2634-x [PubMed: 25199947]

18. Nguyen KT, Gamblin TC, Geller DA. World review of laparoscopic liver resection-2,804 patients. Ann Surg. 2009; 250(5):831-41. DOI: 10.1097/SLA.0b013e3181b0c4df [PubMed: 19801936]

19. Mehta VV, Fisher SB, Maithel SK, Sarmiento JM, Staley CA, Kooby DA. Is it time to abandon routine operative drain use? A single institution assessment of 709 consecutive pancreaticoduodenectomies. J Am Coll Surg. 2013; 216(4):635-42. discussion 42-4. DOI: 10.1016/j.jamcollsurg.2012.12.040 [PubMed: 23521944]

20. van der Wilt AA, Coolsen MM, de Hingh IH, van der Wilt GJ, Groenewoud H, Dejong CH, et al. To drain or not to drain: a cumulative meta-analysis of the use of routine abdominal drains after pancreatic resection. HPB (Oxford). 2013; 15(5):337-44. DOI: 10.1111/j.1477-2574.2012.00609.x [PubMed: 23557407]

21. Van Buren G 2nd, Bloomston M, Hughes SJ, Winter J, Behrman SW, Zyromski NJ, et al. A randomized prospective multicenter trial of pancreaticoduodenectomy with and without routine intraperitoneal drainage. Ann Surg. 2014; 259(4):605-12. DOI: 10.1097/SLA.0000000000000460 [PubMed: 24374513]

22. Ferrero A, Russolillo N, Vigano L, Sgotto E, Lo Tesoriere R, Amisano M, et al. Safety of conservative management of bile leakage after hepatectomy with biliary reconstruction. $\mathrm{J}$ Gastrointest Surg. 2008; 12(12):2204-11. DOI: 10.1007/s11605-008-0586-8 [PubMed: 18642049]

23. Vigano L, Ferrero A, Sgotto E, Tesoriere RL, Calgaro M, Capussotti L. Bile leak after hepatectomy: predictive factors of spontaneous healing. Am J Surg. 2008; 196(2):195-200. DOI: 10.1016/j.amjsurg.2007.08.062 [PubMed: 18466874]

24. Lo CM, Fan ST, Liu CL, Lai EC, Wong J. Biliary complications after hepatic resection: risk factors, management, and outcome. Arch Surg. 1998; 133(2):156-61. [PubMed: 9484727]

25. Li SQ, Liang LJ, Peng BG, Lu MD, Lai JM, Li DM. Bile leakage after hepatectomy for hepatolithiasis: risk factors and management. Surgery. 2007; 141(3):340-5. DOI: 10.1016/j.surg. 2006.08.013 [PubMed: 17349845]

26. Capussotti L, Ferrero A, Vigano L, Sgotto E, Muratore A, Polastri R. Bile leakage and liver resection: Where is the risk? Arch Surg. 2006; 141(7):690-4. discussion 5. DOI: 10.1001/archsurg. 141.7.690 [PubMed: 16847242]

27. Kubo S, Sakai K, Kinoshita H, Hirohashi K. Intraoperative cholangiography using a balloon catheter in liver surgery. World J Surg. 1986; 10(5):844-50. [PubMed: 3776221]

28. Yamashita Y, Hamatsu T, Rikimaru T, Tanaka S, Shirabe K, Shimada M, et al. Bile leakage after hepatic resection. Ann Surg. 2001; 233(1):45-50. [PubMed: 11141224] 
Table 1

Characteristics among Patients with and without Bile Leak $(\mathrm{N}=6859)$

\begin{tabular}{|c|c|c|c|}
\hline & Bile Leak $(n=530)$ & No Leak $(n=6329)$ & p-value \\
\hline Age, Median (IQR) & $60(50-69)$ & $60(50-68)$ & 0.285 \\
\hline Female Sex, n (\%) & $260(49.1)$ & $3,286(51.9)$ & 0.205 \\
\hline BMI, Median (IQR) & $27.6(23.7-31.1)$ & $27.3(23.9-31.5)$ & 0.800 \\
\hline \multicolumn{4}{|l|}{ Race/Ethnicity, n (\%) } \\
\hline White & $350(77.3)$ & $4,076(76.9)$ & \\
\hline Black & $43(9.5)$ & $489(9.2)$ & \\
\hline Asian & $29(6.4)$ & $323(6.1)$ & \\
\hline Hispanic & $31(6.8)$ & $411(7.8)$ & 0.907 \\
\hline Diabetes, n (\%) & $82(15.5)$ & $1,034(16.3)$ & 0.604 \\
\hline Smoking, n (\%) & $68(12.8)$ & $958(15.1)$ & 0.153 \\
\hline Preoperative biliary stent, $\mathbf{n}(\%)$ & $99(18.7 \%)$ & $255(4.1 \%)$ & $<0.001$ \\
\hline Major hepatectomy, n (\%) & $305(57.6)$ & $2,124(33.6)$ & $<0.001$ \\
\hline \multicolumn{4}{|l|}{ Surgical Approach, n (\%) } \\
\hline Open & $464(87.6)$ & $4,725(74.7)$ & \\
\hline Minimally Invasive & $65(12.3)$ & $1,595(25.2)$ & $<0.001$ \\
\hline Perioperative transfusion, $\mathrm{n}(\%)$ & $193(36.4)$ & $1,051(16.6)$ & $<0.001$ \\
\hline Malignant Diagnosis, $\mathrm{n}(\%)$ & $434(81.9)$ & $4,792(75.7)$ & 0.002 \\
\hline Neoadjuvant chemotherapy, n (\%) & $190(36.1)$ & $1,907(30.3)$ & 0.006 \\
\hline Operative time $\geq 225 \min$ (median time), $\mathrm{n}(\%)$ & $387(73.0)$ & $3,056(48.3)$ & $<0.001$ \\
\hline Enterohepatic Reconstruction, n (\%) & $134(25.6)$ & $326(5.2)$ & $<0.001$ \\
\hline Surgical Drain, n (\%) & $443(84.1)$ & $2,593(41.1)$ & $<0.001$ \\
\hline Any Complication, n (\%) & $305(57.6)$ & $1,051(16.6)$ & $<0.001$ \\
\hline Post-hepatectomy liver failure, $\mathrm{n}(\%)$ & $107(20.2)$ & $257(4.1)$ & $<0.001$ \\
\hline Reoperation, $\mathrm{n}(\%)$ & $64(12.1)$ & $142(2.2)$ & $<0.001$ \\
\hline Readmission, $\mathrm{n}(\%)$ & $189(35.7)$ & $534(8.5)$ & $<0.001$ \\
\hline Death, n (\%) & $32(6.0)$ & $106(1.7)$ & $<0.001$ \\
\hline Length of Stay, Median (IQR) & $9(6-15)$ & $5(4-7)$ & $<0.001$ \\
\hline Sepsis or Septic Shock, n (\%) & $150(28.3)$ & $304(4.8)$ & $<0.001$ \\
\hline
\end{tabular}

J Gastrointest Surg. Author manuscript; available in PMC 2019 April 01. 


\begin{tabular}{llll}
\hline & Bile Leak $(\mathbf{n}=\mathbf{5 3 0})$ & No Leak $(\mathbf{n}=\mathbf{6 3 2 9})$ & p-value \\
\hline Deep/Organ Space SSI, $\mathrm{n}(\%)$ & $202(38.1)$ & $303(4.8)$ & $<0.001$ \\
\hline
\end{tabular}

IQR: interquartile range; BMI: body mass index; HCT: hematocrit 
Table 2

Bile Leaks among Patients after Major Hepatectomy $(\mathrm{n}=2429)$

\begin{tabular}{|c|c|c|c|}
\hline & Bile Leak $(n=305)$ & No Leak $(n=2124)$ & p-value \\
\hline \multicolumn{4}{|l|}{ Surgical Approach, n (\%) } \\
\hline Open & $277(90.8)$ & $1,852(87.3)$ & \\
\hline Minimally Invasive & $28(9.2)$ & $269(12.7)$ & 0.081 \\
\hline \multicolumn{4}{|l|}{ Diagnosis, $\mathrm{n}(\%)$} \\
\hline Benign & $42(13.8)$ & $430(20.3)$ & \\
\hline Malignant & $263(86.2)$ & $1,692(79.7)$ & 0.007 \\
\hline Enterohepatic Reconstruction, n (\%) & $104(34.1)$ & $223(10.5)$ & $<0.001$ \\
\hline Surgical drain, $\mathrm{n}(\%)$ & $258(84.6)$ & $1,084(51.2)$ & $<0.001$ \\
\hline Neoadjuvant chemotherapy, n (\%) & $120(39.3)$ & $794(37.6)$ & 0.504 \\
\hline Operative time $\geq 225 \min$ (median time), $\mathrm{n}(\%)$ & $256(83.9)$ & $1,476(69.5)$ & $<0.001$ \\
\hline Perioperative transfusion, $\mathrm{n}(\%)$ & $125(41.0)$ & $545(25.7)$ & $<0.001$ \\
\hline
\end{tabular}


Table 3

Logistic Regression model for perioperative morbidity after hepatectomy ${ }^{\dagger}$

\begin{tabular}{l|l|l|l|l}
\hline Variable & Odds ratio & 95\% CI min & 95\% CI max & $p$ value \\
\hline Univariate & & & & \\
\hline Bile leak & 6.81 & 5.66 & 8.19 & $<0.001$ \\
\hline Perioperative transfusion & 3.51 & 3.07 & 4.02 & $<0.001$ \\
\hline Operative time & 1.005 & 1.004 & 1.005 & $<0.001$ \\
\hline Major hepatectomy & 2.07 & 1.84 & 2.34 & $<0.001$ \\
\hline Enterohepatic reconstruction & 6.35 & 5.22 & 7.72 & $<0.001$ \\
\hline Multivariable & & & & \\
\hline Bile leak & 4.55 & 3.72 & 5.56 & $<0.001$ \\
\hline Perioperative transfusion & 2.29 & 1.96 & 2.67 & $<0.001$ \\
\hline Operative time & 1.002 & 1.0017 & 1.0029 & $<0.001$ \\
\hline Major hepatectomy & 1.19 & 1.03 & 1.37 & 0.015 \\
\hline Enterohepatic reconstruction & 2.81 & 2.23 & 3.53 & $<0.001$ \\
\hline
\end{tabular}

${ }^{\dagger} \mathrm{C}$-statistic for model is 0.73 
Table 4

Logistic Regression model for mortality after hepatectomy ${ }^{\dagger}$

\begin{tabular}{l|l|l|l|l}
\hline Variable & Odds ratio & 95\% CI min & 95\% CI max & $\boldsymbol{p}$ value \\
\hline Univariate & & & & \\
\hline Bile leak & 3.77 & 2.51 & 5.66 & $<0.001$ \\
\hline Any complication & 29.6 & 18.0 & 48.7 & $<0.001$ \\
\hline Liver failure & 22.5 & 15.8 & 32.0 & $<0.001$ \\
\hline Reoperation & 17.5 & 11.8 & 25.9 & $<0.001$ \\
\hline Multivariable & & & & \\
\hline Bile leak & 0.77 & 0.48 & 1.22 & 0.262 \\
\hline Any complication & 15.2 & 8.92 & 25.8 & $<0.001$ \\
\hline Liver failure & 7.05 & 4.75 & 10.5 & $<0.001$ \\
\hline Reoperation & 3.59 & 2.28 & 5.63 & $<0.001$ \\
\hline${ }^{*}$ C-statistic for model is 0.90 & & &
\end{tabular}

${ }^{\dagger} \mathrm{C}$-statistic for model is 0.90 